Scientific Journal Warsaw University of Life Sciences - SGGW

Problems of World Agriculture volume 18 (XXXIII), number 4, 2018: 146-151 DOI: 10.22630/PRS.2018.18.4.105

Irina Glazkova $^{1}$, Dorota Koziol-Kaczorek ${ }^{2}$, Sergey Shmatko ${ }^{3}$

${ }_{1,3}$ North-Caucasus Federal University, Russian Federation

${ }^{2}$ Warsaw University of Life Sciences - SGGW, Poland

\title{
Smart Contracts as a New Technology in the Digital Economy
}

\begin{abstract}
Digital technologies have a number of advantages that contribute to the development of the economy and make it more transparent. Some of the main features of modern digital technologies are speeding up business processes, reducing costs, eliminating the possibility of fraud, ensuring the transparency of the system and the ability to check and analyze the system. Regardless of whether a commercial or government organization uses the technology, in any case, there is a wide range of possibilities of its application. One of these technologies is blockchain. A blockchain is a distributed database in which storage devices are not connected to a shared server. This database stores an ever-growing list of ordered records called blocks. Each block contains a timestamp and a link to the previous block. The article defines a smart contract, describes the main areas of its application and provides processes similar to smart contracts, but working outside the blockchain. We also consider some of the risks that arise when working with smart contracts.
\end{abstract}

Key words: smart contract, cryptocurrency, blockchain

JEL Classification: D86, G23, O16, O31

\section{Introduction}

Technological progress does not stand still and over the past 20 years we have witnessed the rapid development of the Internet, which undoubtedly influenced both our daily lives and ways of doing business. Mentioned technological progress include also the emergence of e-Commerce.

According to the Decree of the President of the Russian Federation dated 09.05.2017 № 203 "On the Strategy of development of the information society in the Russian Federation for 2017 - 2030" the current system of management should be transformed into a digital economy. The digitalization is, for example, the key factor of production because processing of large volumes data in digital form and the use of such analysis results can significantly improve the efficiency of production, technology, equipment, storage, sale, delivery of goods and services. The Decree of President of The Russian Federation marked the beginning of intensive use of information and communication technologies by state bodies, business and citizens (Babkin et al., 2017). As part of this trend, the main way to ensure the efficiency of economic activity of the subject should be the introduction of data processing technologies that will reduce costs in the production of goods and services. This

\footnotetext{
${ }^{1} \mathrm{PhD}$; Department of Business Informatics, North-Caucasus Federal University, Brusneva 13-52 St., Stavropol, Russian Federation, e-mail: iu.glazkova@gmail.com; https://orcid.org/0000-0001-5721-9300

$2 \mathrm{PhD}$; Department of Agricultural Economics and International Economic Relations, Faculty of Economic Sciences WULS-SGGW, Nowoursynowska 166 St., 02-787 Warszawa, e-mail: dorota_koziol@sggw.pl; https://orcid.org/0000-0001-7582-0810

${ }^{3} \mathrm{PhD}$; Department of Business Informatics, North-Caucasus Federal University, Brusneva 13-52 St., Stavropol, Russian Federation, e-mail: sshmatko@yandex.ru
} 
requirement has determined the relevance of this paper, the purpose of which is the economic justification of the effectiveness of the use of distributed registers and smart contracts in the course of economic activities of entities. Today we are witnessing the development and implementation of completely new technologies that can change the world, as the Internet did in its time. One such technology is the technology of the blockchain. In this paper we present only a basic characteristic of blockchain and smart contracts.

\section{The blockchain}

For the first time, the term blockchain appeared as the name of a fully replicated distributed database implemented in the Bitcoin system. This explain why the blockchain is often referred to transactions in various cryptocurrencies, but the technology of block chains can be extended to any interconnected information blocks (Genkin et al., 2017). Bitcoin was the first application of blockchain technology in October 2008 (Iansiti et al., 2017).

Blockchain technology ensures that data will not be changed during transmission. Therefore, it can find application not only in the field of Finance, but also in other areas, including real estate and health. However, the financial sector is, if not the most promising, then the most solvent source of demand for smart contracts. Many business processes in the industry are still accompanied by piles of related securities, which complicate doing business, and make up a significant share of the revenue of intermediaries. Blockchain offers special features that are called smart contracts. The introduction of smart contracts can simplify these processes, so the major players themselves have started to develop in this area. Smart contracts are automatically created in the system, copied to different stores, and executed using distributed computing. Therefore, after the execution of the smart contract it cannot be corrected, even if later it is found vulnerabilities.

A smart contract is an automatically used process that provides all possible options for the development of events and there is no possibility of making amendments. This term appeared in the article of the American cryptographer Nick Szabo, which was published in 1994. According to Nick Szabo's idea, self-executing smart contracts, first of all, must fulfill the specified conditions of the "contract", reducing the number of costs and errors associated with the human factor. At the same time, smart contracts should save the world from intermediaries who are now involved in the performance and enforcement of the obligation in one way or another. In addition, Nick Szabo believed that with the advent of smart contracts virtually disappear all sorts of fraudulent transactions.

Like any other contract, a smart contract has its own objects.

- Signatories. Signatories are parties to a smart contract that accept or waive the terms using electronic signatures. A direct analogue is the signature of the sender of funds in the Bitcoin network, which confirms the transaction in the chain of blocks (Babkin et al., 2017).

- Subject of contract. The subject of the contract can only be an object within the environment of the smartest contract, or it must be ensured unhindered, direct access of the smart contract to the subject of the contract without human intervention. This is the most difficult issue that could not be solved before the advent of cryptocurrencies in 2009. 
- Conditions. The terms of the smart contract must have a full mathematical description, which can be programmed in the environment of the smart contract. It is in the conditions described the logic of execution of the points of the subject of the contract.

A prerequisite for such contracts is the existence of a specific execution environment. Certain conditions are required:

- The use of widespread electronic signature methods based on public and private keys (asymmetric encryption).

- Existence of open, decentralized and trusting databases for executed transactions, the operation of which completely excludes the human factor. As an example: blockchain in Bitcoin.

- Decentralization of the smart contract execution environment. As an example: Ethereum, Codius, Counterparty.

- Reliability of the digital data source. As an example: root SSL certification authorities in databases of modern Internet browsers.

A smart contract can update the data in the blockchain in accordance with the initially set rules - for example, transfer digital assets from one participant to another. As soon as the new technology gains momentum, smart contracts will make a real digital revolution, which will be comparable to the invention of HTML, which radically changed the Internet, and later the entire world economy.

Proponents of smart contracts argue that many of their types can be made partially or completely self-executing and self-sufficient. Smart contracts based on cryptography can provide better security than traditional contracts based on the law, and reduce other transaction costs associated with the conclusion of contracts and possible legal costs.

According to the British magazine The Economist, smart contracts have the prospect of becoming the most important application of blockchain technology (Genkin et al., 2017).

The use of smart contracts in their activities helps various companies in many areas of life to simplify their activities. For example, the R3 consortium, which includes 45 large financial institutions, is developing in the field of blockchain application in the financial industry. More than 15 participating banks have developed prototypes of smart contracts for factoring operations, providing participants with the opportunity to see the data on transactions in real time. At the same time, in parallel, banks are also conducting their internal development:

- Barclays uses smart contracts to automate the payment and the change of right to possession during the transaction.

- $\quad \mathrm{HSBC}$ and Bank of America replaced letters of credit with smart contracts (written guarantee from the payer's Bank to the payee's Bank) (Golikova et al., 2017).

In Russian Federation, the technology has also been developed. Last year, Alfa-Bank and S7 conducted the first financial transaction using blockchain in Russia. Two smart contracts were used at once-for opening and execution (closing) of the letter of credit. Interacting with each other smart contracts are designed to reduce the negative consequences of a potential error in the code of one of them.

Smart contracts are quite seriously considered as an alternative to existing exchanges for transactions with securities. Given the fact that securities are currently virtually all virtualized and exist only in the form of electronic registers, the transfer of securities trading to the blockchain is only a matter of time. 
As an example, we will give the first transaction with securities in Russia with the use of smart contracts in the blockchain, held on September 29, 2017. This transaction was carried out by «National settlement Depository» and consisted of execution of Raiffeisenbank's order to purchase MegaFon bonds (Butenko, 2014).

The use of smart contracts is now possible in theory even in the election system. According to experts, it is almost impossible to falsify the election results, but thanks to smart contracts, it is possible to completely exclude the possibility of external interference in the voting system. In such a case, the votes would be placed in a distributed register and would require exceptional computing power to decode them. There are no such computers, so it will be impossible to hack this system.

The full implementation of smart contracts in the election system is not yet a prospect for the nearest future. However, public services are already working hard on the most obvious advantage of the blockchain - reliable storage of documents. Thus, the Swedish cadastral service (Lantmäteriet), together with ChromaWay blockchain startup, Kairos Future consulting firm and Telia mobile provider, is working on its own blockchain solution. It is designed to eliminate errors related to manual data entry and improve the reliability of document transmission. At the same time, digital documentation of the transfer of real estate to the property is carried out with the help of the developed ChromaWay system of smart contracts.

Since 2017, Moscow has been testing a blockchain platform for voting on urban governance issues in the Active citizen system. Russian Prime Minister Dmitry Medvedev believes that the emergence of distributed Ledger technology can have long - term consequences: «in a few years, cryptocurrencies may disappear, and the technology on the basis of which they develop - the blockchain will become part of everyday reality».

Smart contracts certainly have their advantages. The advantages of this type of contract are as follows:

- The safety. The smart contract is encrypted and stored in a distributed manner, which guarantees protection against loss or unauthorized modification.

- The cheapness and speed. Most processes are automated, and most intermediaries are eliminated from the process.

- The standardization. Today, there are many options for smart contracts, and you can choose the right one for a specific task.

\section{The risk of smart contracts}

However, despite its power and attractiveness, smart contracts are a source of risks. An only few types of risk is considered bellow.

\section{Risk 1. Errors in the development of smart contracts}

The rules of writing smart contracts are not formalized at the moment, but the main thing is that the rules of their verification are not described. However, it is not possible to make changes to the smart contract because it is by definition immutable.

The simplest example: a smart contract is concluded, under the terms of which the buyer reserves the amount to transfer money when the goods arrive at the warehouse. But the program code of the smart contract was written with an error - the procedure for checking the receipt of goods to the warehouse was not implemented. As a result, the 
money paid by the buyer, but the seller will never get, regardless of whether he delivered the goods or not delivered. Money for the seller lost. Especially carefully should be developed and smart contracts should be tested at ICO (Biswas et al., 2016).

\section{Risk 2. Compromising the oracles}

Oracle programs are specialized services designed to bind the digital world to the real world and provide smart contracts with input data for their execution. The question of the immutability and authenticity of the data received from these services.

For example, an attacker could attack an Oracle that provides currency exchange rate data for currency exchange contracts. After changing its code, it will produce incorrect data, which entails quite specific financial risks for smart contracts that use this data.

You can also replace the information or modify the physical information that comes to the entrance of the Oracle. The simplest example is to cover with a light-proof object the sensor of the Oracle transmitting information about the illumination to the smart contract of the "Smart city". In this case, the Oracle will constantly assume that it is dark and, as a result, the smart contract will not extinguish street lights.

\section{Risk 3. The loss of access}

All work with the blockchain is based on the fact that you can authorize yourself in the system only using the private part of the cryptographic key. If, in the case of ordinary contracts, transactions, etc., it is possible to authorize with the help of third parties (court, authorities issuing documents, notary, recommendations, etc.), in the case of blockchain and smart contracts, such a possibility is not provided. If the private part of the key is lost, you will never be able to recover it.

\section{Risk 4. Lack of legal framework}

Non-performance of a normal contract in the real world may be subject to legal proceedings. The world of blockchain is currently not an object of the legal field. All transactions conducted within the framework of smart contracts are provided only by the good will of the participants.

\section{Risk 5. No possibility of risk insurance}

Due to the fact that at the moment the legal field when working with the blockchain is not defined, there is no risk insurance in this market. In the event of any risk events with a smart contract, all financial consequences are entirely borne only by its participants.

\section{Summary}

Blockchain systems, as well as smart contracts, are good for ensuring interaction of subjects without using intermediaries, but their life is limited by the appearance of artificial intelligence. After the birth of a developed, devoid of feelings and interest in artificial intelligence, a place as an arbitrator and Trustee will be occupied by him.

Thus, as a result of the analysis of the use of smart contracts by business entities and evaluation of its result, it can be concluded that this mechanism has a positive impact on the competitiveness of any business entity, as cost reduction increases the potential and sustainability of the organization. In other words, as a result of reducing costs on the above grounds, the organization will be able to effectively use the available funds for the expansion of economic activities, which will lead to an increase in profits. 
In this paper we present only a basic characteristic of blockchain and smart contracts. More detailed and comprehensive analyzes are in preparation.

\section{References}

Babkin, A.V., Burkaltseva, D.D., Pshenichnikov, W.W., Tyulin, A.S. (2017). Cryptocurrency and blockchain technology in digital economy: development genesis (in Russian). St. Petersburg State Polytechnical University Journal. Economics, 10(5), 9-22. DOI:10.18721/JE.10501.

Biswas, K., Muthukkumarasamy, V. (2017). Securing Smart Cities Using Blockchain Technology. IEEE 18th International Conference on High Performance Computing and Communications; IEEE 14th International Conferenceon Smart City; IEEE 2nd International Conference on Data Science and Systems (HPCC/SmartCity/DSS), Sydney, NSW, 1392-1393.

Butenko, E.D. (2014). Bitcoin. State and prospects of cryptocurrency development (in Russian). Finance and Credit, 20(23), 44-47.

Christidis, K., Devetsikiotis, M. (2016). Blockchains and Smart Contracts for the Internet of Things. IEEE Access, 4, 2292-2303.

Genkin, A., Mikheev, A. (2017). Blockchain. How it works and what awaits us tomorrow. Alpina Publisher, Moscow.

Golikova, O.M., Fedotova, A.I. (2017). Is it possible for cryptocurrency based on the technology of blockchain to solve the problem of information security in the financial sector? (in Russian). ITportal, $3,3$.

Iansiti, M., Lakhani, K.R. (2017). The Truth About Blockchain. Harvard Business Review. January-February, 118-127.

\section{For citation:}

Glazkova I., Kozioł-Kaczorek D., Shmatko S. (2018). Smart Contracts as a New Technology in the Digital Economy. Problems of World Agriculture, 18(4), 146-151;

DOI: $10.22630 /$ PRS.2018.18.4.105 